\title{
The Moderation Effect of Athletic Maturity on the Association between Perceived Leadership Behavior and Athlete Satisfaction
}

\author{
Stavroula Ntomali ${ }^{1,3}$, Maria Psychountaki ${ }^{1}$, Miltiades Kyprianou ${ }^{2} \&$ Chrysoula Chairopoulou ${ }^{1,3}$ \\ ${ }^{1}$ The School of Physical Education \& Sport Science, National and Kapodistrian University of Athens, Athens, \\ Greece \\ ${ }^{2}$ Biostatistician, Athens, Greece \\ ${ }^{3}$ Department of Aquatic Sports, National and Kapodistrian University of Athens, Athens, Greece \\ Correspondence: Stavroula Ntomali, The School of Physical Education \& Sport Science, National and \\ Kapodistrian University of Athens, Ethnikis Antistasis 41, 17237, Daphne, Athens, Greece. Tel: \\ 30-210-727-6061. E-mail: sdomali@phed.uoa.gr
}

Received: September 6, 2017

doi:10.5539/ijps.v9n4p24
Accepted: October 2, $2017 \quad$ Online Published: October 17, 2017

URL: http://doi.org/10.5539/ijps.v9n4p24

\begin{abstract}
Perceived leadership behavior and athlete satisfaction are integral constructs in the multidimensional leadership model. The aim of the present study was to examine the moderation effect of athletic maturity on the association between perceived leadership behavior and athlete satisfaction in synchronized swimming athletes. The sample was comprehensive, as it included all 165 Greek synchronized swimming athletes participating in national championships and elite athletes from the national teams participating in international events. Athletic maturity was classified according to the athletes' category into comen, junior and senior. Athlete satisfaction was measured with Athletes Satisfaction Scale and perceived leadership behavior was assessed with the Leadership Scale for Sports-Perceived edition. The questionnaires were completed at the end of the competitive season at the athletes' training grounds. Results showed that the strength of association between perceived leadership behavior and athlete satisfaction is significantly greater in the senior category as compared to the comen and junior categories. This association proves to be stronger for the dimension of satisfaction with leadership that is adequately explained by the factors of social support and training and instruction. The findings provide support to the notion that athletic maturity is a moderator of the effect of perceived leadership behavior on athlete satisfaction.
\end{abstract}

Keywords: athletic maturity, athlete satisfaction, leadership, moderation

\section{Introduction}

Leadership, as defined by Barrow (1977, p. 232) is "the behavioral process of influencing individuals and groups toward set goals". As Northouse points out (2015), it is important to conceptualize leadership as a process, but not as a trait or characteristic, occurring in groups and involving influence. Leadership is a fundamental aspect of sports performance, particularly within team sport environments (Cotterill \& Fransen, 2016) and has been studied in individual and team sports, in amateur and professional levels and within different age categories for both genders.

In this aspect, a widely used paradigm is the multidimensional model of leadership, developed and evolved by Chelladurai (Chelladurai, 1978, 1990; Chelladurai \& Carron, 1978). The model proposes that athlete's satisfaction and performance are dependent on the compatibility between leadership behaviors (required, actual, and preferred) (Arripe-Longueville, Fournier, \& Dubois, 1998). From this point of view, the athlete is the most important factor in any athletic program or activity (Bebetsos \& Theodorakis, 2003; Chelladurai \& Riemer, 1997) and his/her satisfaction represents "a positive affective state resulting from a complex evaluation of the structures, processes, and outcomes associated with the athletic experience" (Chelladurai \& Riemer, 1997, p. 135). Therefore, the athlete's satisfaction with leadership and personal outcome are the two primary endpoints in Chelladurai's model (satisfaction with leadership and satisfaction with personal outcome). These are measured with the Scale of Athlete Satisfaction (SAS) developed by Chelladurai, Imamura, Yamaguchi, Oinuma, and Miyauchi (1988). 
According to the model, the above constructs should be dependent on the athlete's perceived leadership behavior (Chelladurai, 1990). The latter is measured by the Leadership Scale for Sports (LSS; Chelladurai \& Carron, 1981; Chelladurai \& Saleh, 1978, 1980) and contains five dimensions of leader behavior: (i) training and instruction, (ii) democratic behavior, (iii) autocratic behavior, (iv) social support, and (v) positive feedback. The interaction between LSS and SAS is in itself multidimensional, even if it comprises only a part of Chelladurai' s model and has been the primary object of interest in several studies (Horne \& Carron, 1985; Nazarudin, Fauzee, Jamalis, Geok, \& Din, 2009; Riemer \& Chelladurai, 1995; Schliesman, 1987). Athlete satisfaction has also been studied in conjunction with the athlete-coach relationship (Chelladurai, 1984; Dwyer \& Fischer, 1990; Eys, Loughead, \& Hardy, 2007), the team and its performance (Chelladurai, 1984; Weiss \& Friedrichs, 1986), personal outcome (Chelladurai et al., 1988) and cohesion and motivation of participation (Carron, 1984; Carron \& Chelladurai, 1981).

Although this was not explicitly stated in all cases, several potential moderators of the association between perceived leadership behavior and athlete satisfaction have been studied. For example, gender differences were examined by Vilani and Samulski (2005), sport type by Chelladurai (1984) and Dwyer and Fischer (1990), coach's and player's status by Horne and Carron (1985) and culture by Chelladurai et al. (1988). A potential moderator that has undergone considerable investigation is athletic maturity. Athletic maturity is a cornerstone in Hersey's and Blanchard's situational leadership theory (1969), where they state that for leaders to be effective they must adapt the leadership style according to the level of readiness of the followers (Hersey \& Blanchard, 1977). Reverting to the athlete as the pivotal point of view, Chelladurai and Saleh (1978) and Chelladurai and Carron (1983) found that the athlete's preferences in the leadership styles of their coaches alter as athletic maturity changes from the competitive levels of elementary, high school, university and professional sport.

The above provide evidence to the following two associations: a) between athlete satisfaction and the athlete's perception of the coach's leadership behavior, and b) between athletic maturity and the athlete's preference of the coach's leadership behavior. Therefore, the aim of the present study was to investigate whether athletic maturity is a potential moderator of the strength of association between athlete perceived leadership behavior and athlete satisfaction or not.

From a research point of view, an area, which has yet to be explored in Greece, concerns female athletes of synchronized swimming, now renamed as artistic swimming (FINA, 2017) with regards to the above hypothesis. These athletes have to attain a high degree of collaboration and synchronization, which can only be achieved through the consistent and vigilant supervision by the coach.

\section{Methods}

\subsection{Participants}

The sample consisted of 165 Greek synchronized swimming female athletes from 20 teams. The sample size included all athletes participating in national championships, as well as all the elite athletes - members of the Greek National Teams. Their mean age were $16.2 \pm 3.8$ years ranging from 13 to 29 years. The swimmers' classification into competition categories, according to the rules of the Ligue Européenne de Natation (LEN) was the following: comen (13-14 years, $\mathrm{n}=75)$, junior $(15-17$ years, $\mathrm{n}=54)$ and senior category (18 years and over, $\mathrm{n}=36$ ). Inclusion criteria in the study required that the participants were active athletes, had more than two years athletic experience and had competed in a minimum of four national championships.

\subsection{Questionnaires}

\section{(a) Leadership Scale for Sports (LSS)}

The LSS (Chelladurai \& Saleh, 1980) measures the athletes'perceptions of their coaches' leadership styles. The synchronized swimmers completed the Greek version of the LSS-Perceived Edition (Aggelonidis, Zervas, Kakkos, \& Psychountaki, 1996). The scale consists of 40 items, in which answers were given in a Likert type 5-point scale from 1 (always) to 5 (never). Athletes were instructed to respond to the questionnaires based on how they presently perceived the leadership behavior of their current coach. The instrument measures five constructs of leadership behavior: (i) training and instruction, (ii) democratic behavior, (iii) autocratic behavior, (iv) social support and (v) positive feedback. The internal consistency estimates, measured by Cronbach's alpha coefficients, for the original validated Greek perceived version were $0.94,0.83,0.67,0.84$, and 0.88 for the five factors respectively. In the present study, the internal consistency estimates were $0.84,0.80$, $0.67,0.75$ and 0.80 , correspondingly.

(b) Athletes Satisfaction Scale (SAS) 
The SAS (Chelladurai et al., 1988), measures the satisfaction that athletes feel as a member of a team. Athletes completed the Greek version (Theodorakis \& Bebetsos, 2003) of the questionnaire. They were instructed to indicate the extent of their satisfaction on a 7-point Likert type scale ranging from 1 (extremely dissatisfied) to 7 (extremely satisfied). The scale consists of 10 items and includes two dimensions: (i) satisfaction with leadership and (ii) satisfaction with personal outcome. Analysis of the original Greek version supported the internal consistency of the scales ( 0.95 for satisfaction with leadership and 0.83 for satisfaction with personal outcome). In the present study, the internal consistency estimates were 0.90 and 0.61 respectively.

\subsection{Procedure}

Initial recruitment of athletes was made by contacting the head coach and the team manager of each swimming club. After receiving the initial approval, a 15-minute meeting with the athletes and their parents was arranged in which their consent was given since most athletes were underage. The meeting involved a briefing about the purpose of the study and all the necessary instructions for completing the questionnaires. After the athletes were assured that their participation was voluntary and confidential, they filled in a form concerning their athletic profile. During a second meeting, the athletes completed the two questionnaires for about 30 minutes in their club training grounds, without their parents and coaches. The questionnaires were completed at the end of the competitive season.

The study was approved by the Faculty Review Board.

\subsection{Statistical Analysis}

Since there were three groups of athletes (comen, junior, and senior categories), the demographics among the three groups were compared with the ANOVA test followed by post-hoc pairwise comparisons with Bonferroni correction. The association among the five factors of Perceived Leadership Behavior and the two factors of Athletes Satisfaction was examined with the MANOVA procedure of canonical correlations. Accordingly, the dependence of Satisfaction with Leadership on the factors of Perceived Leadership Behavior was examined with stepwise regression models. Both multivariate models were applied separately for each of the three competition categories and the differences in the strength of the effects were examined through comparison of the corresponding correlation coefficients. The level of significance was set at 0.05 .

\section{Results}

Table 1 describes the athletic profile of the synchronized swimming athletes. The 165 athletes were trained by 20 coaches, of which only two were male.

Table 1. Characteristics $(\mathrm{M} \pm \mathrm{SD})$ of synchronized swimming athletes for the three competition categories (comen, junior, and senior category) and for the total sample

\begin{tabular}{lcccc}
\hline & Comen & Junior & Senior & Total \\
& Category & Category & Category & Sample \\
\hline Number of athletes & 75 & 54 & 36 & 165 \\
Age (years) & $13.4 \pm 0.5$ & $15.9 \pm 0.8$ & $22.4 \pm 2.9$ & $16.2 \pm 3.8$ \\
Athletic experience (years) & $5.5 \pm 1.9$ & $8.4 \pm 1.9$ & $12.5 \pm 4.1$ & $8.0 \pm 3.7$ \\
Number of competitions & $9.8 \pm 4.0$ & $23.3 \pm 10.7$ & $50.9 \pm 27.3$ & $23.3 \pm 21.3$ \\
Training years with their current coach & $3.1 \pm 1.8$ & $4.5 \pm 2.7$ & $5.1 \pm 3.3$ & $4.0 \pm 2.6$ \\
Age at first competition & $7.9 \pm 1.8$ & $7.5 \pm 1.9$ & $9.9 \pm 4.3$ & $8.2 \pm 2.8$ \\
Solo (\%) & $4(5.3 \%)$ & $2(3.7 \%)$ & $1(2.8 \%)$ & $7(4.2 \%)$ \\
Duet -Team-Combo (\%) & $34(45.3 \%)$ & $3(5.6 \%)$ & $2(5.6 \%)$ & $39(23.6 \%)$ \\
All Events (\%) & $37(49.3 \%)$ & $49(90.7 \%)$ & $33(91.7 \%)$ & $119(72.1 \%)$ \\
\hline
\end{tabular}

Means in age, athletic experience, number of competitions and training years with the current coach are significantly different among groups (ANOVA, $p<0.01$ ), with each group, as post-hoc pairwise comparisons with Bonferroni corrections show, being significantly different to both of the other groups. 
Figures 1 through 3 show the results of the canonical correlations of the MANOVA model with the two factors of athlete satisfaction as the dependent variables and the five factors of the perceived leadership behavior as the independent predictors. Figure 1 refers to the athletes in the comen category, Figure 2 is for the junior category and Figure 3 is for the senior category. The multivariate tests of significance, expressed through the values of Pillai's trace, showed in all cases significant associations between the two groups of variables. The three models are practically the same in nature but different in the strength of associations between the covariates and the dependent variables. In all three cases, the associations are expressed through a unique canonical correlation originating from all five factors of the perceived leadership behavior and explaining both factors of athlete satisfaction. The loading of autocratic behavior is negative, but the most important correlations derive from social support and training and instruction. The correlations with satisfaction with leadership are greater than the correlations with satisfaction with personal outcome.

The value of the canonical correlation for the senior category $(R=0.84)$ is significantly greater than the corresponding values for the comen $(R=0.58, P=0.004)$ and junior $(R=0.65, P=0.023)$ categories. The proportion of variance in the dependent variables explained by canonical variable was far greater for the senior category $(50.7 \%)$ in comparison to the other two categories (in both cases, $21.5 \%)$.

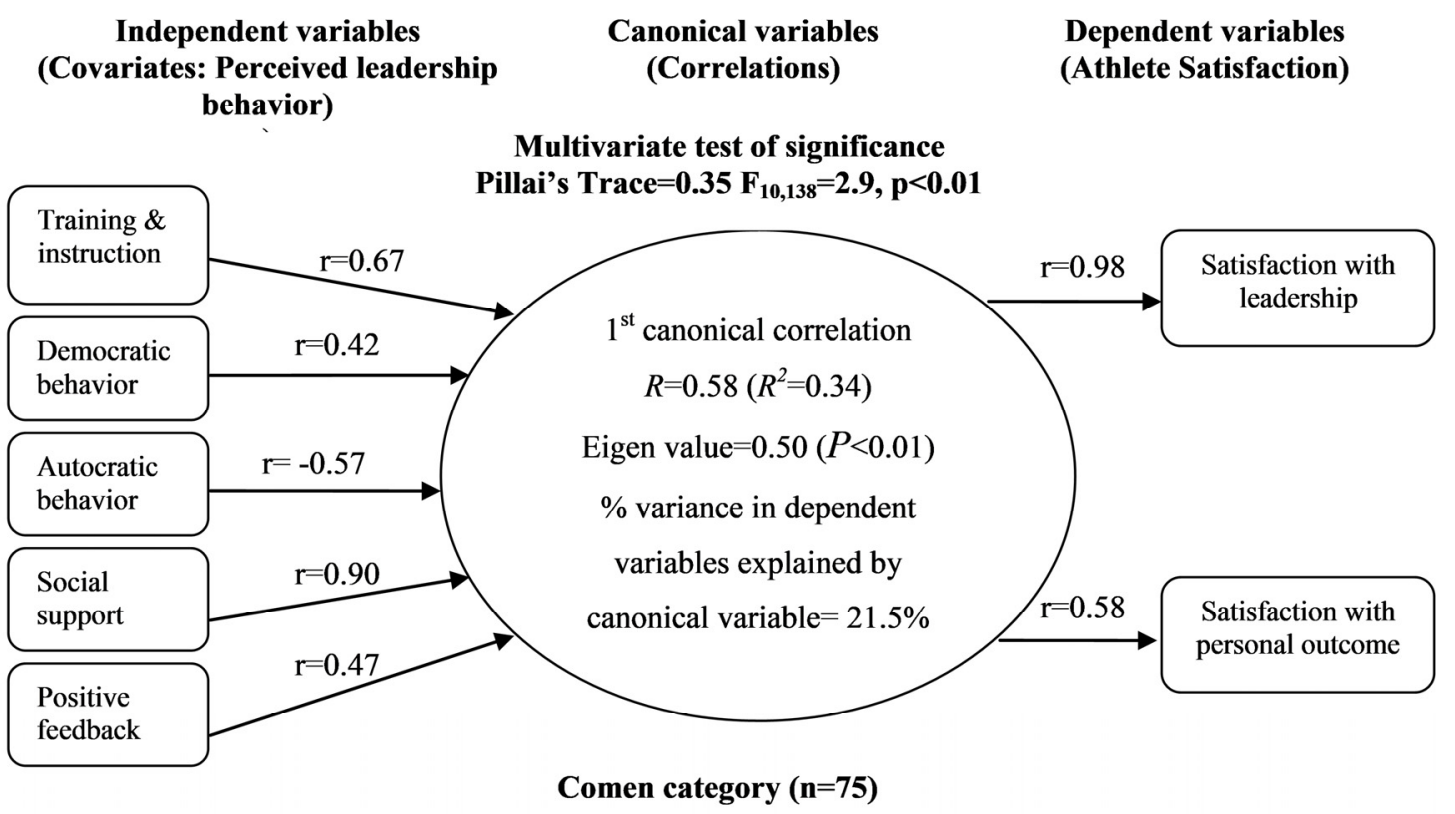

Figure 1. Canonical correlations model between the factors of the Perceived Leadership Behavior and Athlete Satisfaction for the comen category 


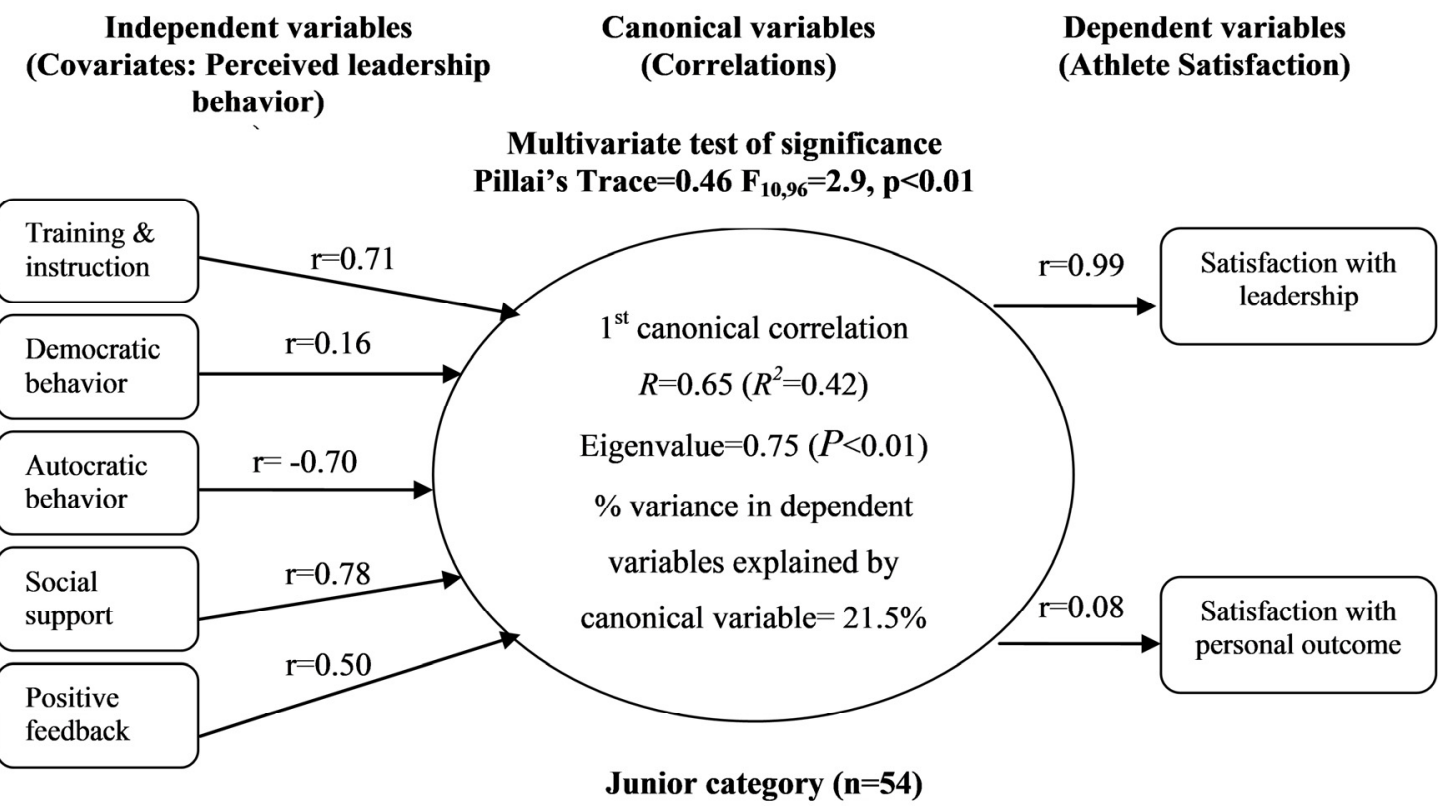

Figure 2. Canonical correlations model between the factors of the Perceived Leadership Behavior and Athlete

Satisfaction for the junior category

Independent variables

(Covariates: Perceived

Leadership Behavior)

\section{Canonical variables \\ (Correlations)}

Multivariate test of significance

Pillai's Trace $=0.80 \mathrm{~F}_{10,60}=4.0, p<0.01$

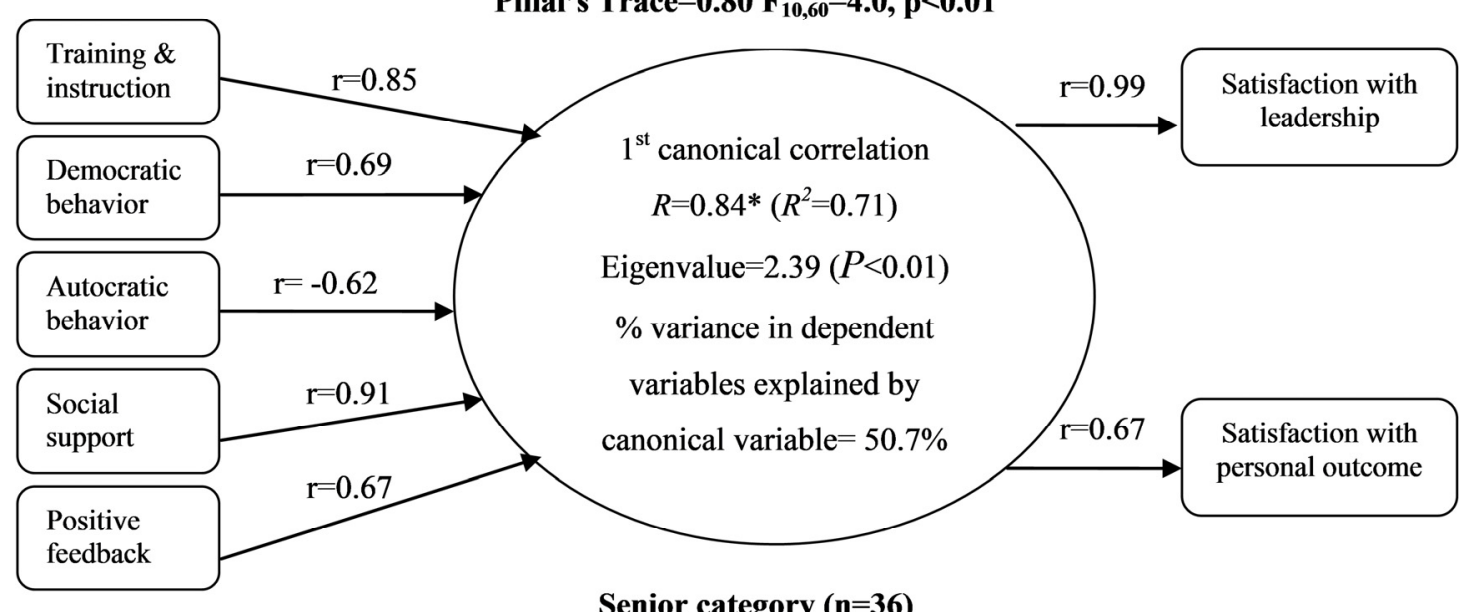

Senior category $(n=36)$

Figure 3. Canonical correlations model between the factors of the Perceived Leadership Behavior and Athlete Satisfaction for the senior category

*-The coefficient for the senior category is significantly greater than for the comen and the junior categories at $p<0.05$.

Likewise, the multivariate stepwise linear regression analysis of the factor satisfaction with leadership as the dependent variable revealed in all three cases that two factors from the perceived leadership behavior (social support and training and instruction) enter the regression equation (Table 2). As with the canonical correlations model, the value of the multiple $R$ for the senior category $(R=0.80)$ was significantly greater than the corresponding values for the comen $(R=0.56, p=0.013)$ and junior $(R=0.59, p=0.030)$ categories. 
The improvement of the regression model from the comen and junior categories to the senior category can also be inferred from relative changes in the values of the coefficients (slopes) and the intercepts in the three regression equations. There is an increase of values of the coefficients and a simultaneous decrease in the values of the intercept.

Table 2. Results of the stepwise linear regression analysis with "Satisfaction with leadership" as the dependent variable and the factors of the "Perceived Leadership Behavior" as the independent predictors

\begin{tabular}{lccccc}
\hline Category & Intercept & Social Support & Training \& Instruction & $R$ & $R^{2}$ \\
\hline Comen $(\mathrm{n}=75)$ & 3.72 & 0.41 & 0.30 & 0.56 & $31.4 \%$ \\
Junior $(\mathrm{n}=54)$ & 1.96 & 0.53 & 0.57 & 0.59 & $34.8 \%$ \\
Senior $(\mathrm{n}=36)$ & 0.62 & 0.86 & 0.58 & $0.80 *$ & $64.0 \%$
\end{tabular}

*-The coefficient for the senior category is significantly greater than for the comen and the junior categories at $p<0.05$.

\section{Discussion}

The present study examined whether the association between perceived leadership behavior and athlete satisfaction in synchronized swimming athletes was moderated by athletic maturity or not, the latter being expressed through three distinct competition categories: comen, junior, and senior. The findings provided evidence that the hypothesis stated here, held its ground in the studied sample, in the sense that the strength of association between perceived leadership behavior and athlete satisfaction was significantly greater in the senior category as compared to the comen and junior categories. This association proves to be stronger for satisfaction with leadership and that is adequately explained by the factors of social support and training and instruction.

The association between perceived leadership behavior and athlete satisfaction is an integral part of the multidimensional model of leadership (Chelladurai, 1978), therefore, it is not surprising that quite a few articles have studied the particular relationship in very different situations and in various sports, always reporting similar findings, supporting the existence of the association. To site a few, Weiss and Friedrichs (1986) studied the relationship in collegiate basketball teams, Dwyer and Fischer (1990) in wrestlers, Vilani and Samulski (2005) in table tennis, Schliesman (1987) in university level track and field athletes and Chelladurai et al. (1988) in various sports (badminton, basketball, hockey, swimming, track and field, volleyball and wrestling).

However, the main finding of the current study is not the existence of the association between perceived leadership behavior and athlete satisfaction per se, but the moderation of the strength of the association that is instrumented by the athletes' athletic maturity level. Moderation exists because the three categories are actually very different in practically every aspect of what one might label as athletic maturity. In the sense of human physiological and psychological growth as reflected by age, girls in the comen category are still in their late puberty, juniors are in their adolescence while seniors are already young women. Differences in athletic experience and number of competitions reflect variations in athletic maturity. Finally, differences in the number of training years with their current coach might also reflect alterations in the maturity of relationships.

Turman (2001), based on both the situational and multidimensional leadership theories, studied the impact of success and athlete maturity level on coaches' leadership styles over time. This implies that in the specific study the dependent and independent variables were reversed with the persisting effect of athletic maturity. There is no reason to question this approach, as it seems more logical to assume that the association between perceived leadership behavior and athlete satisfaction works in both directions.

It also seems logical to assume that the athletes' perception of leadership behavior will have a more direct impact on their satisfaction with leadership than on their satisfaction with personal outcome, since the latter is expected to be associated with other factors, not directly related to the coach-athlete relationship. The two factors that seem to have the most significant effect on athlete satisfaction with leadership are social support and training and instruction. The positive influence of social support and training and instruction on athlete satisfaction, together with positive feedback, was also reported by Black and Weiss (1992) and Riemer and Chelladurai (1995). Similar findings were reported in two other studies (Chelladurai, 1984, 1993) with regards to training and instruction and positive feedback, but not social support. The fact that in the current study the athletes' perception of the coaches' social support is the most important factor influencing their satisfaction with leadership, can be partly connected to the peculiarities of the sport under investigation. Synchronized swimming is a difficult sport, requiring many 
hours and years of practice in order to participate in a handful of contests and competitions each year with a program ranging from two to four minutes according to the competition category and the athletic event. Remaining a "non-profitable" vocation and not a profession, a female synchronized swimmer, beyond her love for the sport needs, as time goes by, more social support from her coach.

The present article does not aspire to provide an exhaustive methodology in moderation. To this end, it would be an omission not to mention Paul E Jose's book "Doing statistical mediation and moderation" published in 2013 (Jose, 2013) that offers a comprehensive presentation of the concepts and uses of mediation and moderation, providing straightforward practical examples. The present study follows a distinct approach to examine a very specific question, namely the existence of moderation effect of the synchronized swimmers' athletic maturity on the association between perceived leadership behavior and athlete satisfaction.

We should bear in mind that, with regards to the specific sport, the present study encompasses practically all synchronized swimmers in Greece. Thus, from the point of the moderating effect of athletic maturity on the association between perceived leadership behavior and athlete satisfaction, in the specific sport in Greece, the study is pretty much conclusive. Undoubtedly, ethnic, cultural, and religious differences and different sports may add their own moderation weights (Baker, Yardley, \& Cote, 2003; Khalaj, Khabiri, \& Sajjadi, 2011; Nazarudin, Fauzee, Jamalis, Geok, \& Din, 2009).

\section{Conclusion}

Figure 4 basically summarizes the findings of the current study. In a comprehensive sample of Greek synchronized female swimmers, athletic maturity seems to be instrumental as a moderator variable strengthening the association between perceived leadership behavior and athlete satisfaction that constitute integral constructs in the multidimensional leadership model.

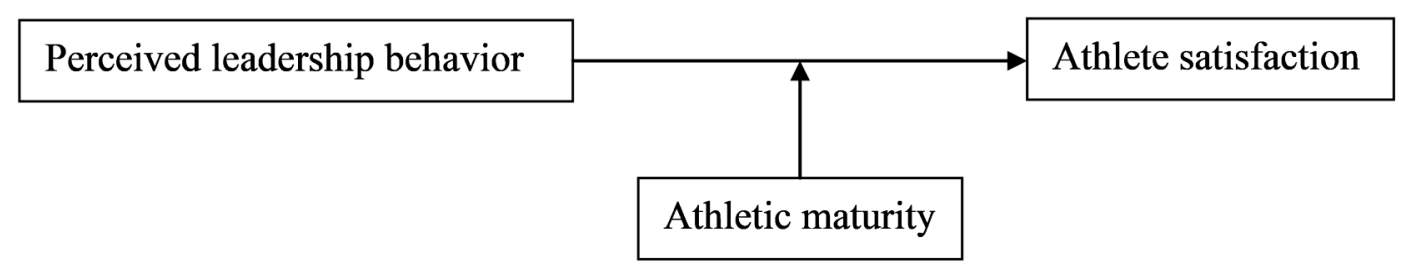

Figure 4. The moderation effect of athletic maturity on the association between perceived leadership behavior and athlete satisfaction

\section{References}

Aggelonidis, Y., Zervas, I., Kakkos, B., \& Psychountaki, M. (1996). Validity and reliability of the Leadership Sport Scale-Perceived Leadership Behavior. In I. Theodorakis, \& A. Papaioannou (Eds.), Proceedings of $1^{\text {st }}$ International $/ 4^{\text {th }}$ Hellenic Congress of Sports Psychology: Komotini (pp. 232-237).

Arripe-Longueville, F., Fournier, J. F., \& Dubois, A. (1998). The perceived effectiveness of interactions between expert French judo coaches and elite female athletes. The Sport Psychologist, 12(3), 317-332. https://doi.org/10.1123/tsp.12.3.317

Baker, J., Yardley, J., \& Côté, J. (2003). Coach behaviors and athlete satisfaction in team and individual sports. International Journal of Sport Psychology, 34, 226-239.

Barrow, J. C. (1977). The variables of leadership: A review and conceptual framework. Academy of Management Review, 2(2), 231-251.

Bebetsos, E., \& Theodorakis, N. (2003). Athletes' satisfaction among team handball players in Greece. Perceptual and Motor Skills, 97, 1203-1208. https://doi.org/10.2466/pms.2003.97.3f.1203

Black, S. J., \& Weiss, M. R. (1992). The relationship among perceived coaching behaviors, perceptions of ability, and motivation in competitive age-group swimmers. Journal of Sport \& Exercise Psychology, 14, 309-325. https://doi.org/10.1123/jsep.14.3.309

Carron, A. V. (1984). Motivation: Implications for coaching and teaching. London, ON: Sport Dynamics. 
Carron, A. V., \& Chelladurai, P. (1981). Cohesiveness, coach-athlete compatibility, participation orientation, and their relationship to relative performance and satisfaction. In Psychology of Motor Behavior and Sport-1982 (p. 86). College Park, Maryland: North American Society for the Psychology of Sport and Physical Activity.

Chelladurai, P. (1990). Leadership in sports: A review. International Journal of Sport Psychology, 21, 329.

Chelladurai, P. (1978). A contingency model of leadership in athletics (Unpublished doctoral dissertation). Department of Management Sciences, University of Waterloo, Canada.

Chelladurai, P. (1984). Discrepancy between preferences and perceptions of leadership behavior and satisfaction of athletes in varying sports. Journal of Sport Psychology, 6, 27-41. https://doi.org/10.1123/jsp.6.1.27

Chelladurai, P. (1990). Leadership in sports: A review. International Journal of Sport Psychology, 21, 328-354.

Chelladurai, P. (1993). Leadership. In R. N. Singer, M. Murphy, \& L. K. Tennant (Eds.), Handbook of research on sport psychology (pp. 647-671). New York: Macmillan Publishing Company.

Chelladurai, P., \& Carron, A. V. (1978). Leadership. Ottawa: Sociology of Sport Monograph Series, Canadian Association for Health, Physical Education and Recreation.

Chelladurai, P., \& Carron, A. V. (1981). Task characteristics and individual differences, and their relationship to preferred leadership in sports. In G. C. Roberts, \& D. M. Landers (Eds.), Psychology of motor behavior and sport-1980 (p. 87). Champaign, IL: Human Kinetics.

Chelladurai, P., \& Carron, A. V. (1983). Athletic maturity and preferred leadership. Journal of Sport Psychology, 5, 371-380. https://doi.org/10.1123/jsp.5.4.371

Chelladurai, P., \& Riemer, H. A. (1997). A classification of facets of athlete satisfaction. Journal of Sport Management, 11, 133-159. https://doi.org/10.1123/jsm.11.2.133

Chelladurai, P., \& Saleh, S. (1980). Dimensions of Leader Behavior in Sports: Development of a Leadership Scale. Journal of Sport Psychology, 2, 34-45. https://doi.org/10.1123/jsp.2.1.34

Chelladurai, P., \& Saleh, S. D. (1978). Preferred leadership in sports. Canadian Journal of Applied Sport Sciences, 3, 85-92.

Chelladurai, P., Imamura, H., Yamaguchi, Y., Oinuma, Y., \& Miyauchi, T. (1988). Sport leadership in a cross-national setting: The case of Japanese and Canadian university athletes. Journal of Sport \& Exercise Psychology, 10, 374-389. https://doi.org/10.1123/jsep.10.4.374

Cotterill, S., \& Fransen, K. (2016). Athlete Leadership in Sport Teams: Current Understanding and Future Directions. International Review of Sport and Exercise Psychology, 9(1), 16-133. https://doi.org/10.1080/1750984X.2015.1124443

Dwyer, J. M., \& Fischer, D. G. (1990). Wrestlers' perceptions of coaches' leadership as predictors of satisfaction with leadership. Perceptual and Motor Skills, 71, 511-517. https://doi.org/10.2466/pms.1990.71.2.511

Eys, M. A., Loughead, T. M., \& Hardy, J. (2007). Athlete leadership and satisfaction in interactive sport teams. Psychology of Sport \& Exercise, 8, 281-296. https://doi.org/10.1016/j.psychsport.2006.04.005

Fédération internationale de notation. (2017). Fina Artistic Swimming Rules 2017-2021, 1-93.

Hersey, P., \& Blanchard, K. H. (1977). Management of Organizational Behavior (3rd ed.). Englewood C1iffs, N.J.: Prentice-Hall, Inc.

Hersey, P., \& Blanchard, K. H. (1969). Life cycle theory of leadership. Training and Development Journal, 23, 26-34.

Horne, T., \& Carron, A. V. (1985). Compatibility in coach-athlete relationships. Journal of Sport Psychology, 7 , 137-149. https://doi.org/10.1123/jsp.7.2.137

Jose, P. E. (2013). Doing Statistical Mediation and Moderation. Guilford Publications Inc.

Khalaj, G., Khabiri, M., \& Sajjadi, N. (2011). The relationship between coaches' leadership styles \& player satisfaction in women skate championship. Procedia Social and Behavioral Sciences, 15, 3596-3601. https://doi.org/10.1016/j.sbspro.2011.04.341

Nazarudin, M. N. B. H., Fauzee, M. S. O., Jamalis, M., Geok, S. K., \& Din, A. (2009). Coaching leadership styles and athlete satisfactions among Malaysian university basketball team. Research Journal of International Studies, 9, 4-11.

Northouse, P. G. (2015). Leadership: Theory and practice. Thousand Oaks, CA: Sage Publications. 
Riemer, H. A., \& Chelladurai, P. (1995). Leadership and satisfaction in athletics. Journal of Sport \& Exercise Psychology, 17, 276-293. https://doi.org/10.1123/jsep.17.3.276

Schliesman, E. S. (1987). Relationship between the congruence of preferred and actual leader behavior and subordinate satisfaction with leadership. Journal of Sport Behavior, 10(3), 157-166.

Theodorakis, N., \& Bebetsos, E. (2003). Examination of Athletes' Satisfaction: A first approach. Inquiries in Sport \& Physical Education, 1(2), 197-203.

Turman, P. D. (2001). Situational coaching styles. The impact of success and athlete maturity level on coaches' leadership styles over time. Small Group Research, 32(5), 576-594. https://doi.org/10.1177/104649640103200504

Vilani, L. H. P., \& Samulski, D. M. (2005). Situational Leadership П and the Coach-Athlete Relationship in Brazilian Table Tennis. Sport Science Research, 26(3), 31-36.

Weiss, M. R., \& Friedrichs, W. D. (1986). The influence of leader behaviors, coach attributes, and institutional variables on performance and satisfaction of collegiate basketball teams. Journal of Sport Psychology, 8, 332-346. https://doi.org/10.1123/jsp.8.4.332

\section{Copyrights}

Copyright for this article is retained by the author(s), with first publication rights granted to the journal.

This is an open-access article distributed under the terms and conditions of the Creative Commons Attribution license (http://creativecommons.org/licenses/by/4.0/). 